\begin{tabular}{|l|l|}
\hline & \\
\hline
\end{tabular}

SEÇÃO: APRESENTAÇÃO DO DOSSIÊ

\title{
Dossiê: Imprensa, cultura e circulação de ideias
}

\author{
Dossier: Press, culture and circulation of ideas \\ Dossier: Prensa, cultura y circulación de ideas
}

Isabel Lustosa'
orcid.org/0000-0003-2456-6925
isabellustosa@gmail.com

\section{Marlise Regina Meyrer² orcid.org/0000-0002-6446-7799 marlise.meyrer@pucrs.br}

Recebido em: 13 abr. 2020. Aprovado em: 13 abr. 2020 Publicado em: 25 ago. 2020.

\section{(c) (i)}

Artigo está licenciado sob forma de uma licença Creative Commons Atribuição 4.0 Internacional.
Este dossiê foi proposto, tendo por norte os objetivos do grupo de pesquisa inscrito no Conselho Nacional de Desenvolvimento Cientíico e Tecnológico (CNPq): Imprensa e circulação de ideias o papel dos periódicos nos séculos XIX e XX que reúne cerca de 90 pesquisadores nacionais e estrangeiros, distribuídos em várias linhas de estudos, para pensar a imprensa impressa periódica de grande circulação em suas conexões nacionais e internacionais. Proposto pela linha de pesquisa O Brasil e as Américas, o dossiê aqui apresentado reúne artigos que ultrapassam os limites desta última, apresentando temas que envolvem não só a imprensa ibero-americana, mas também aspectos mais gerais do fazer jornal e do fazer jornalismo.

Demos aos artigos selecionados uma organização cronológica, mas que acaba por atender também a uma divisão temática. $\mathrm{O}$ artigo de Karen Racine transporta a questão para a década de 1820, em Birghman, na Inglaterra, a nação mais poderosa do mundo e berço da imprensa periódica. Em um contexto tanto de expansão da imprensa como de novas experiências pedagógicas, jovens estudantes, filhos da elite de uma América hispânica revolucionada foram enviados para o estrangeiro, a fim de estudar numa escola progressiva chamada Hazelwood onde produziram um curioso jornal, o Hazelwood Magazine, que alinhado com os objetivos cívicos e pedagógicos da escola, pretendia formar os cidadãos de bom caráter dentro da lógica revolucionária liberal. Do outro lado do mundo, no Brasil, o embate que se verificava entre as elites de um Maranhão ainda divido entre a adesão à independência brasileira e a fidelidade a Portugal, aparece nas páginas do jornal longevo - para os padrões do tempo -, o Conciliador do Maranhão. Exemplo que demonstra como as notícias e o debate constitucional tiveram uma circulação transatlântica que incluia os pontos mais distantes desse imenso país, como o demonstra o artigo de Marcelo Cheche. Na corte do Rio de Janeiro, uma imprensa incipiente, mas de grande atividade agitaria a cena da independência. Um dos personagens de maior destaque foi João Soares Lisboa, redator do 
Correio do Rio de Janeiro que liderou o movimento pela convocação de uma constituinte brasileira, a partir de um abaixo-assinado apresentado a d. Pedro. Soares Lisboa foi um difusor da cultura política das luzes e, em seu artigo, Paula Caricchio apresenta e discute a forma como as ideias de Civique Gastine foram difundidas no Brasil através as páginas do Correio do Rio de Janeiro.

Dentro do mesmo recorte temporal, século $X I X$, reunimos os artigos que contemplam o papel da evolução das técnicas de impressão e da especialização das atividades jornalísticas que sucederam aos embates travados na imprensa do Primeiro Reinado. O uso da litografia pela imprensa periódica possibilitou o surgimento e a popularização das revistas ilustradas dando vez a um elenco de caricaturistas e ilustradores especialmente estrangeiros, que tornariam bem mais animada a cena impressa brasileira. Um dos que aqui aportou, em 1875, foi Rafael Bordalo Pinheiro, maior nome da caricatura portuguesa do XIX. Rosangela de Jesus analisa as dificuldades de adaptação de Bordalo Pinheiro em um ambiente já consolidado em que outros artistas já tinham conquistado renome. Com a multiplicação de jornais e revistas ao longo do século XIX, os empregos nas tipografias para profissionais do ramo também se multiplicaram. Exercendo uma profissão que requeria o bom conhecimento da língua, os tipógrafos foram uma das primeiras categorias a se organizar e a publicar seus próprios jornais. Tania de Luca analisa esse processo a partir do estudo de uma das publicações do gênero, a Revista Tipográfica, que circulou no Rio de Janeiro entre 1888 e 1890, revelando a forma como os tipógrafos viam a profissão e como avaliavam o avanço da arte tipográfica no Brasil. O progresso da imprensa no dezenove também levou a uma especialização setorial com destaque para a imprensa esportiva uma das que primeiro se firmou. Sendo o famoso esporte bretão o que viria a se tornar o mais popular no Brasil, Victor Melo apresenta as adaptações que o futebol sofreu, comparando as informações que a imprensa fluminense fornecia sobre a prática daquele esporte na Inglaterra, na França e na
Argentina. Em 1898, a realização, em Lisboa, do Congresso Internacional da Imprensa, como nos revela Adelaide Machado, seria um fator de reconhecimento da grande transformação que a imprensa sofrera ao longo do século XIX: o jornalismo tinha se firmado como profissão independente; fora criado um estilo jornalístico de escrita e a própria imprensa se convertera um negócio altamente lucrativo dando origem às grandes empresa jornalísticas.

A segunda parte de nosso dossiê se ocupa do século $X X$ e se divide entre quatro artigos. Os dois primeiros voltados para o tema da imigração em dois contextos bem diferentes. A politica de imigração europeia iniciada por d. Pedro II teve grande impulso no final do século XIX. O artigo de Rosane Marcia Neuman nos apresenta curiosa publicação aparecida em Leipzig, na Alemanha, em 1902 e 1903. Era assinada pelo dono de uma empresa de colonização, Hermann Meyer, com o objetivo de fazer propaganda das vantagens de imigrar para o Brasil. Em sua publicação, Meyer reproduz artigos e cartas de e/imigrantes alemães, membros da colônia criada por ele, entre os municipios de Cruz Alta e Palmeira, no Rio Grande do Sul. Uma outra imigração, bem diversa foi a que, depois da Segunda Guerra Mundial, deu origem a uma colônia formada por certa de 2500 pessoas que se estabeleceram no município de Guarapuava, no Paraná, no hoje distrito de Entre Rios. Esse distrito foi fundado, entre março de 1951 e janeiro de 1952, justamente para acolher aqueles imigrantes. Os membros dessa colônia se identificam coletivamente como suábios do Danúbio e eram oriundos de áreas da antiga lugoslávia, Hungria e Romênia. Marcos Nestor Stein em seu artigo, apresenta e analisa as narrativas desses imigrantes publicadas em 1991 e 1992 no Jornal de Entre Rios em comemoração aos 40 anos de fundação daquele distrito.

O uso da imprensa para a desconstrução de imagem de um político é contemplado com dois artigos que falam sobre Getúlio Vargas em dois periodos momentos distintos. George Seabra escreve sobre o jornal Anhanguera, principal veículo de divulgação do ideário do movimento 
bandeirante que se apropriava de representações literária dos bandeirantes paulistas com finalidades políticas. $O$ autor apresenta o perfil de alguns de seus membros, analisa a forma como divulgam seu ideário e mostra como o jornal foi recebido por militares e civis. Destaca ainda o papel de Anhanguera na construção da imagem negativa de Getúlio Vargas, em contraste com a do candidato paulista à Presidência da República, Armando de Salles Oliveira, nas eleições de 1937, abortadas pelo golpe do Estado Novo. Outro Getúlio Vargas, eleito presidente em 1951 e já transformado pela história, será o alvo dos ataques do jornal Correio da Manhã. Luiz Carlos dos Passos Martins, mostra em seu artigo como aquele jornal fundando no final do século XIX, seria uma das trincheiras de combate a Vargas e ao próprio regime democrático.

Finalmente, mas não menos importante, é a contribuição que nos traz de Cuba Yaneidys Arencibia Coloma, que nos revela um pouco do que era a imprensa que se fazia na ilha, antes da revolução de Fidel. A autora nos apresenta a Jorge Manach, jornalista, editor e intelectual de grande influência no seu país, destacando o caráter de ensaística cultural que caracterizava seus escritos, seus vínculos com vários projetos editoriais e sua ação decisiva no sentido de que fosse criada a Universidad del Aire. Esse artigo nos ajuda a conhecer o gradual processo de autonomia e de legitimação do pensamento cultural cubano, além de contribuir para nos mostrar formas especificas de sociabilidade intelectual, originadas pela atuação de Manach em seu tempo.

Temos o privilégio de encerrar esse número com uma entrevista com Celia Del Palácio Montiel, importante pesquisadora da história da imprensa mexicana, fundadora da Red de Historiadores de la Prensa en Iberoamérica (1999) e, desde 2018 , coordenadora do Grupo Temático Historia de la Comunicación, da Asociación Latinoamericana de Investigadores de la Comunicación (ALAIC) e autora de inúmeras publicações. Nesta entrevista, Célia del Palácio reafirma a importância da imprensa como campo estratégico fundamental para a história e demonstra como esse campo de estudos vem se consolidando na América Latina. A historiadora também destaca o papel dos estudiosos da imprensa no atual contexto mundial' "A los estudiosos de los medios toca analizar a profundidad lo que ocurre, desde la academia, denunciar los ataques a la libertad de expresión y presentar la evidencia en los foros más allá del reducido espacio académico"3. Esperamos que este Dossiê seja uma contribuição à essa tarefa.

Endereço para correspondência

Isabel Lustosa

Rua Fonte da Saudade, 265/apto 302,

Lagoa, 22471210

Rio de Janeiro, RJ, Brasil

Marlise Regina Meyrer

Pontificia Universidade Católica do Rio Grande do Sul Av. Ipiranga, 6.681, Prédio 8, sala 405.6

Partenon, 97010082

Porto Alegre, RS, Brasil

3 PALÁCIO, Célia Del. Depoimento de Célia Del Palácio. Destinatários: Marlise Regina Meyrer e Helder V. Gordim da Silveira. [S. L.], 7 abr. 2020. 1 mensagem eletrônica. 